\title{
IIISGUC.ORG
}

"İȘ, GÜC̣" ENDÜSTRi ilLișKiLERI VE INSAN KAYNAKLARI DERGISi

"IS, GUC" INDUSTRIAL RELATIONS AND HUMAN RESOURCES JOURNAL

\section{Kültürün EKY'ye Etkileri ve Türk Pilotların Hofstede Kültür Boyutları Açısından Durumları}

\author{
The Effects of Culture on CRM programs: \\ A Study Investigating Turkish Pilots in terms of Cultural \\ Dimensions Suggested by Hofstede
}

\section{Eyüp Bayram ȘEKERLİ}

Öğr. Gör./ Muğla Üniversitesi, Dalaman Meslek Yüksekokulu

\section{Ender GEREDE}

Yrd. Doç. Dr./Anadolu Üniversitesi, Sivil Havacılık Yüksekokulu

Ocak/January 2011, Cilt/Vol: 13, Say1/Num: 1, Page: 17-38

ISSN: 1303-2860, DOI: 10.4026/1303-2860.2010.0163.x

Makalenin on-line kopyasına erişmek için:

http://www.isguc.org/?p=article\&id=437\&vol=13\&num=1\&year=2011

To reach the on-line copy of article:

http://www.isguc.org/?p=article\&id=437\&vol=13\&num=1\&year=2011

Makale İçin İletişim/Correspondence to: 
(C) 2000- 2011

"İşGüç" Endüstri İlişkileri ve İnsan Kaynakları Dergisi

"İşGüç" Industrial Relations and Human Resources Journal

Ocak/January 2011, Cilt/Vol: 13, Say1/Num: 1

ISSN: 1303-2860, DOI: 10.4026/1303-2860.2010.163.x

Editör/Editor-in-Chief

Aşkın Keser (Kocaeli University)

Editör Yardımcıları/Co-Editors

K.Ahmet Sevimli (Uludağ University)

Gözde Yılmaz (Kocaeli University)

Uygulama/Design

Yusuf Budak (Kocaeli Universtiy)

\author{
Yayın Kurulu / Publishing Committee \\ Dr.Zerrin Firat (Uludăg University) \\ Doç.Dr.Aşkın Keser (Kocaeli University) \\ Prof.Dr.Ahmet Selamoğlu (Kocaeli University) \\ Yrd.Doç.Dr.Ahmet Sevimli (Uludağ University) \\ Yrd.Doç.Dr.Abdulkadir Şenkal (Kocaeli University) \\ Yrd.Doç.Dr.Gözde Yilmaz (Kocaeli University) \\ Dr.Memet Zencirkıran (Uludağ University)
}

Uluslararası Danışma Kurulu / International Advisory Board

Prof.Dr.Ronald Burke (York University-Kanada)

Assoc.Prof.Dr.Glenn Dawes (James Cook University-Avustralya)

Prof.Dr.Jan Dul (Erasmus University-Hollanda)

Prof.Dr.Alev Efendioğlu (University of San Francisco-ABD)

Prof.Dr.Adrian Furnham (University College London-İngiltere)

Prof.Dr.Alan Geare (University of Otago- Yeni Zellanda)

Prof.Dr. Ricky Griffin (TAMU-Texas AEM University-ABD)

Assoc. Prof. Dr. Diana Lipinskiene (Kaunos University-Litvanya)

Prof.Dr.George Manning (Northern Kentucky University-ABD)

Prof. Dr. William (L.) Murray (University of San Francisco-ABD)

Prof.Dr.Mustafa Özbilgin (University of East Anglia-UK)

Assoc. Prof. Owen Stanley (James Cook University-Avustralya)

Prof.Dr.Işık Urla Zeytinoğlu (McMaster University-Kanada)

Danışma Kurulu / National Advisory Board

Prof.Dr.Yusuf Alper (Uludağ University)

Prof.Dr.Veysel Bozkurt (Uludağ University)

Prof.Dr.Toker Dereli (Işık University)

Prof.Dr.Nihat Erdoğmuş (Kocaeli University)

Prof.Dr.Ahmet Makal (Ankara University)

Prof.Dr.Ahmet Selamoğlu (Kocaeli University)

Prof.Dr.Nadir Suğur (Anadolu University)

Prof.Dr.Nursel Telman (Maltepe University)

Prof.Dr.Cavide Uyargil (İstanbul University)

Prof.Dr.Engin Yildırım (Sakarya University)

Doç.Dr.Arzu Wasti (Sabancı University)

Dergide yayınlanan yazllardaki görüşler ve bu konudaki sorumluluk yazarlarına aittir.

Yayınlanan eserlerde yer alan tüm içerik kaynak gösterilmeden kullanılamaz.

All the opinions written in articles are under responsibilities of the outhors.

None of the contents published can't be used without being cited. 


\title{
Kültürün EKY'ye Etkileri ve Türk Pilotların Hofstede Kültür Boyutları Açısından Durumları
}

\author{
The Effects of Culture on CRM programs: \\ A Study Investigating Turkish Pilots in terms of Cultural \\ Dimensions Suggested by Hofstede
}

\author{
Eyüp Bayram ŞEKERLI \\ Öğr. Gör..
}

\begin{abstract}
Özet:
Havayolu sektörü emniyetin ön planda olduğu sektörler arasındadır. Havayolu taşımacıllğında kullanılan teknoloji emniyet seviyesinin yükseltilmesinde önemli bir role sahiptir. Yüksek teknolojiye rağmen, kaza ve kırımlar tamamen önlenememiştir. Araştırmalar insan hatalarını kaza ve kırımların birincil nedeni olarak göstermektedir. İnsan hatalarının nedenlerini araştıran ve yönetilmesinde metotlar geliştiren "İnsan Faktörleri" disiplini kokpit içerisinde hataların önlenmesi için çalışmalar yapmaktadır. Uçuş emniyetini sağlamak, insan hatalarını engellemek ve yönetmek için geliştirilen bir İnsan Faktörleri uygulaması olan Ekip Kaynak Yönetimi (EKY) dünya genelinde birç̧ok havayolu işletmesinde kullanılmaktadır. Fakat bu programların verimliliği ekip üyelerinin kültü̈rel değerlerine uyumlandırılmasına bağhıdır. Ekip Kaynak Yönetimi programları; ulusal, örgütsel ve meslek kültürleri incelenerek tasarlanması gerekmektedir.
\end{abstract}

Anahtar Kelimeler: Sivil Havacıllk Yönetimi, Ekip Kaynak Yönetimi, Uçuş Emniyeti, İnsan Hataları, Ulusal Kültür Boyutları, Türk Pilotları.

\begin{abstract}
:
Airline industry is one of the sectors in which safety is primarily important. In this respect, the use of technology has a significant role in increasing the safety standards to a desired level in air transportation. Unfortunately, these attempts have not been successful in eliminating accidents and incidents completely. Many studies show that the primary reason for these accidents and incidents is human factor. The discipline called "human factors" deals with the precautions that might be taken to prevent human-related errors observed in the cockpit by examining the reasons behind such errors and developing methods for managing these errors. Today, most of the air companies worldwide are using "Crew Resource Management" (CRM) programs designed to establish flight safety and to prevent and manage such possible human-related errors. However, it is commonly believed that the efficiency of such programs depends on how they are adapted to the cultural values of the particular crew it is applied. In other words, CRM programs should be designed after national, organizational and vocational cultures of this particular group are examined thoroughly.
\end{abstract}

Keywords: Civil Aviation Management, Crew Resource Management, Flight Safety, Human Error, Dimensions of National Culture, Turkish Pilots. 


\section{GiRiş}

Havayolu taşımacılığının ekonomik, sosyal ve kültürel çok önemli faydaları bulunmaktadır. Havayolu taşımacılığı pek çok sektörün etkinliğini doğrudan etkilemektedir. Havayolu taşımacılığının bu faydaları sağlayabilmesi ise emniyetin sağlanmasına bağlıdir.

İnsan birçok sistemde emniyeti etkileyen en önemli faktördür. Bu olguyu temel alan SHEL Modeli insanı sistemin merkezine koyarak, çevre, donanım, yazılım ve sistem içerisinde yer alan diğer insanlar ile olan ilişkisini incelemektedir. İnsan (liveware) modelin ortasında yer almaktadır. Günümüzde insan unsuru bilinen birçok sinırlamalara konu olmaktadır. Sistemin çökmemesi için sistemi oluşturan parçaların birbirleri ile uyumlu olmasını sağlamak gerekmektedir. Bu nedenle sistemin merkezinde yer alan insan unsurunun anlaşılması oldukça önemlidir (Hawkins, 2002: 22). Kültür ve tutumlar insanların davranışlarını etkiledikleri için insanın diğer sistem unsurları ile olan etkileşimlerinde önemli bir rol oynamaktadır. Bu nedenle kültür ve tutumlar emniyet etkin davranışlar için oldukça önemli bir hale gelmektedir.

Diğer yandan havayolu taşımacıllğında uçuş emniyetini doğrudan etkileyen en önemli insan grubu pilotlardır. Bu nedenle pilotların diğer sistem unsurları ile etkileşimi dolayısıyla etkisi altında kaldıkları kültür emniyetin sağlanması için son derece önemlidir. Ayrıca yapılan çalışmalar kokpitteki etkileşimlerin kültürden bağımsız olmadığını göstermektedir. Bu durumda kültürün sözü edilen etkileşimleri nasıl etkilediğinin araştırilmasında büyük fayda vardır.

\section{KÜLTÜR KAVRAMI ve HOFSTEDE'NIN KÜLTÜR BOYUTLARI}

Kültür, insan davranışları üzerinde etkili olduğundan insanı ve insan gruplarını inceleyen birçok bilim dalı kültürün tanımını yapmıştır. Bütün bu tanımların ortak özellileri ise, kültürün insan topluluklarını birbirinden ayırt edici bir özelliği olmasıdır. Kültür insan topluluklarının birbirinden faklılaşmasına neden olurken, kendi üyelerini ise birleştirmektedir.
Taylor'un yaptığı tanımda kültür, toplumun üyesi olarak insanoğlunun öğrendiği (kazandığı) bilgi, sanat, gelenek-görenek ve benzeri yetenek, beceri ve alışkanlıkları içine alan karmaşık bir bütün olarak ifade edilmektedir (Güvenç, 1999: 101). Diğer yandan,

Hofstede (2000: 1, 2) ise kültürü; insan grupların birbirinden ayıran kolektif bir zihinsel programlama olarak ifade etmektedir.

Özetle kültür, toplumun belirli bir toplulugun üyeleri ile paylaşılan onları diğer gruplardan ayıran değerler, inançlar, semboller ve davranışlardır. Kültür kişilerin dış çevreye, sosyal hayata uyumunu kolaylaştırarak onların belirli durumlarda belirli davranışları göstermelerini sağlar.

Birçok araştırmacı, kültürel farklılıkları değerlerden yola çıkarak ortaya koymuşlardır. Araştırmacılar değerlerde ve tutumlardaki farklılıkları tespit ederek kültürel sınıflandırmalar, başka bir deyişle "kültürel boyutlar" oluşturmuşlardır. Örnek olarak, Kluckhohn ve Strodtbeck kültürel boyutları; "insanın doğası", "doğayla var olan ilişki", "öncelikli çalışma biçimi", "diğer insanlarla var olan ilişkilerin doğasını" ve "Zamanı algılama boyutu" olarak siralamaktadır (Rogelberg, 2007: 138). Diğer yandan Schwartz (1999:28) ise, kültürel boyutları muhafazakârlık/otonomi, hiyerarşi/egalitaryan ve kontrol kurma/uyum olarak siralamaktadır.

Diğer bir kültürel boyutlandırma çalışması ise, Hofstede (2000) tarafından yapılmıştır. Hofstede, 1967 ve 1980 y1lları arasinda 72 farklı ülkedeki IBM çalışanları üzerinde yaptığ1 araştırmalarda 116,000 adet ankete cevap elde etmiştir. Hofstede (2000: 41), farklı ülkelerdeki IBM çalışanlarının sahip oldukları değerler arasındaki farklılıkları saptamaya çalışmıştır. Hofstede (2000: 29) elde ettiği sonuçları kullanarak ülkeler, meslekler ve cinsiyetler arasındaki farklılıkları sınıflandırmış ve 4 adet kültür boyutu ortaya koymuştur.

Hofstede bunlardan güç mesafesi boyutunu, grup içerisinde gücün eşit olmayan dağlımının derecesi olarak ifade etmektedir. Gücün grup içerisinde göreceli olarak eşit dağılması, düşük güç mesafesi olarak adlandırı- 
lırken, gücün eşit olmayan dağılımı yüksek güç mesafesi olarak tanımlanmaktadır. Belirsizlikten kaçınma boyutu ise, toplumu oluşturan bireylerin belirsizlik durumlarında kendilerini ne kadar tehdit altında hissettiklerini ifade etmektedir. Belirsizlikten kaçınma değerlerinin yüksek olduğu ülkelerde kişilerin daha gergin ve stresli olduğu görülürken belirsizlikten kaçınmanın düşük olduğu toplumlarda insanların daha sakin ve uyumlu eğilimlere sahip oldukları görülmektedir (Hofstede - Soeters, 2002: 3). Hofstede (2000: 29) tarafından belirlenen bir diğer boyut olan bireycilik-kolektivizm boyutunda ise, ülkedeki kişilerin kendi başlarına hareket etmeyi grup olarak hareket etmeye tercih edip etmemeleri ile ilgilidir. Bireyci toplumlarda kişilerin çıkarları grup çıkarlarından daha önemliyken, kolektivist toplumlarda grup ç1karları ve gruba uyum bireyin çıarlarından daha önemlidir. Erkeklik-dişilik boyutu ise, toplum içerisinde baskın olan değerlerin ne kadar erkeksi veya dişil rollerle ilgili olduğunu ifade etmektedir. Erkek kültürlerde; "girişimcilik (atılganlık)", "rekabet", "diğerlerini önemsememe" ve "çok para kazanma" gibi materyalist eğilimler ağır basmaktadır. Dişi kültürlerde ise; "kişiler arasındaki sıcak ilişkiler", "hizmet etme”, "zayıf bireylere karşı ilgi gösterilmesi" ve "dayanışma eğilimleri" ön plana çıkmaktadır.

\section{HOFSTEDE KÜLTÜR BOYUTLARI AÇISINDAN TÜRK KÜLTÜRÜ}

Hofstede'in (2000: 500) araştırmalarında Türkiye; "yüksek güç mesafesi", "düşük bireycilik" "yüksek belirsizlikten kaçınma" ve "dişi özellikler" gösteren ülkeler grubunda yer almaktadır.

Türk Toplumunda güç mesafesinin yüksek olduğunu gösteren diğer bir araştırma Kabasakal ve diğerleri tarafından yapılmıştır. $\mathrm{Bu}$ çalışmada dünya genelinde birçok farklı toplumun kültürel özelliklerini ve bunların liderlik becerilerine yansımalarını tespit etmeyi hedefleyen "GLOBE" araştırma programı kapsamında Türkiye ile ilgili elde edilen sonuçlar Orta Doğudaki bazı ülkelerle ve dünya ortalamalarıyla karşılaştırılmıştır. Araştırma kapsamında güç mesafesi ile ilgili elde edilen en yüksek indeks değeri 5,80, en düşük değer ise 3,25'tir. Türkiye'ye ilişkin elde edilen güç mesafesi değeri 5,57 olarak belirlenmiştir (Dastmalchian-Kabasakal, 2001: 483).

Türk Kültüründeki yüksek güç mesafesi, nispeten daha az güce sahip olan bireylerin otoriteyi eleştirmelerini veya karar alma süreçlerinde kendi fikirlerini beyan edebilmelerini engellemektedir.

Konuya ilişkin Lauter ve Kozan'ın yaptığ1 araştırma ise gerek özel işletmelerde gerekse kamuda çalışanlar arasında otoriter liderlik tipinin ve merkezi karar verme eğilimlerinin baskın olduğunu göstermiştir. Kozan, Türk yöneticilerin otoriteyi mevkiden çok kendi kişiliklerinin bir parçası olarak değerlendirdiklerini belirtmektedir. Yöneticinin astlarından gördüğü saygı onun performansı ile ilgili en önemli göstergelerden birisi olarak kabul edilmektedir (Wasti, 1998: 619).

Hofstede (2000:102), bireylerin üstleri veya içerisinde yer aldıkları grup liderlerine fikirlerini ifade ederken korkup korkmamalarınin güç mesafesi ile ilgili en önemli göstergelerden birisi olduğunu belirtmektedir. Wasti tarafından yapılan araştırma, Türk çalışanların önemli bir bölümünün üstlerine fikirlerini belirtme konusunda çekingen davrandıklarını ortaya koymaktadır (Wasti, 1998:620).

Diğer yandan, Türkiye ve benzeri ülkelerde belirsizliğe karşı toleransı az olan bireyler tehdit edici belirsizliği azaltmak için güç mesafesini açarak tepki vermektedirler. Türkiye'de grubun birey üzerindeki baskısı oldukça fazladır. Diğer yandan grup tarafından oluşturulmuş önceden denenmiş yöntemlere göre davranılması bireylerin yaşayacakları stresi azaltmaktadır. Sargut'un Türk öğrenciler ve yöneticileri konu alan araştırması sonucunda elde ettiği bulgular, Türk insanının önemli ölçüde belirsizlikten kaçınma eğiliminde olduğunu göstermektedir. Türkiye'de yaygın bir uygulama olan "ömür boyu istihdam" belirsizlikten kaçınma eğiliminin doğal bir sonucu olarak ortaya çıkmaktadır (Sargut, 2001: 96).

Hofstede'in (2000: 215) belirlediği kolekti- 
vizm boyutunda ise, Türk kültürü'nün yüksek kollektivist değerlere sahip olduğu görülmektedir. Geleneksel olarak Türk kültürü kişiler arasındaki yakın ilişkileri içermektedir. Türk kültüründe aile, akraba ve komşuluk ilişkilerinin oldukça önemli olduğu görülmektedir. Türk kültüründeki geleneksel sosyalleşme sürecinde bireylerin bağımsızlık eğilimlerinden daha çok itaat, yakın ilişkiler ve ebeveynlere sadakat gibi eğilimler ön plana çıkmaktadır. Örnek olarak, Payaslıoğlu ve Frey tarafından 1958 yılında A.B.D'li ve Türk öğrenciler üzerinde yapılan araştırmalarda, bireyci değerlerin A.B.D'li öğrenciler arasında yaygın olduğu görülürken, aileye ve diğer gruplara sadakatin Türk ögrrenciler arasında daha baskın bir özellik olduğu belirtilmektedir. Fakat, sosyo-ekonomik değişiklikler nedeniyle zaman içerisinde Türk toplumundaki geleneksel kollektivist değerlerin yanı sıra bireyci değerlerin de geliştiği görülmektedir (Karakitapoglu vd., 2002: 335).

Hofstede'in (2000) dişi ve erkek kültür boyutunda yaptığı sinıflandırmada Türkiye; İran, Tayland, Brezilya, İsrail, Fransa, İspanya, Peru, Sili, Yugoslavya vb. ülkelerle birlikte dişi ülkeler grubunda yer almaktadır. Buna karşın, kültürel açıdan Türkiye ile benzerlikleri bulunan; Japonya, Yunanistan, Meksika vb. gibi ülkelerin erkek kültür grubunda sıralandıkları görülmektedir. Fakat, Hofstede'in kümeleri oluştururken farklılıkları da belirlediği görülmektedir. Örneğin, dişi ya da erkek kümelerinde yer alan ülkeleri, daha dişi ya da daha erkek olarak farklılaştırmak olanaklıdır. Türkiye'nin erkeklik-dişilik ayrımının orta s1nırına en yakın ülke olduğu görülmektedir. Özellikle kuzey ülkeleri Türkiye'ye göre daha dişi özellikler göstermektedir (Sargut, 2001: 176).

İlk bakışta Türk toplumunun dişi değerleri konusunda ortaya konan araştırma sonuçları pek inandırıcı gelmemektedir. Sargut (2001: 178), Hofstede'in Türk toplumu üzerine yaptığı genellemeyi test etmek amacıyla, geniş bir zaman aralı̆̆ içerisinde, üniversite öğrencileri üzerinde bir araştırma yapmıştır. Değişik zamanlarda değişik öğrenci gruplardan elde edilen test sonuçları, Türk toplumunun erkek toplum imajina oldukça ters düsen bir tablo oluşturmuştur. Kız öğrenciler geleneksel kadınsı değerlerin egemen olduğu tavır ve davranışları eksiksiz sergilerken, erkeklerin de aynı oranda olmasa bile, kadınsı sayılan değerleri, erkeksi değerlerden önde tuttukları görülmüştür (Sargut, 2001: 178).

Türk kültürünün Hofstede (2000) tarafından belirlenen dört boyuttaki değerleri tutum ve davranışlarına yön vermektedir. Fakat ulusal kültür içerisinden birçok alt kültürel yapının bulunduğunu göz ardı etmemek gerekir. Türk kültürünün pilotlar üzerindeki yansimalarının tespit edilmesi EKY eğitimlerinin daha etkin bir biçimde tasarlanmasını sağlayabilecektir.

\section{EKIP KAYNAK YÖNETIMI VE KÜLTÜRÜN EKIP KAYNAK YÖNETIMI ÜZE- RINDEKI ETKILLERI}

Yapılan araştırmalar uçuş sırasındaki insan-insan etkileşiminden kaynaklanan insan hatalarının emniyeti etkileyen en önemli unsur olduğunu göstermektedir. Ayrıca uçuş ekibinin yaptığ 1 hatalar onların teknik bilgi ve becerilerinden değil daha çok "teknik olmayan becerilerinden" kaynaklanmaktadır. Bu nedenle uçuş ekibinin "teknik olmayan becerilerinin" ve insan-insan etkileşiminin geliştirilmesi emniyetin sağlanması açısından son derece önemlidir. Bu kapsamda uçuş sırasındaki insan hatalarının önlenmesi ve etkilerinin azaltılması amaciyla "Crew Resource Management" (CRM) adı verilen yönetim programları uygulanmaya başlanmıştır.

Ekip Kaynak Yönetimi (EKY) İngiliz Sivil Havacılık Otoritesi CAA (Civil Aviation Authority-CAA: 1) tarafından eldeki kaynakların optimum düzeyde kullanımını sağlayarak uçuş emniyeti ve etkinliğini geliştirmeyi amaçlayan bir yönetim sistemi olarak tanımlanmaktadır. EKY, Lauber (1984: 20)tarafından eldeki bilgi, araç-gereç ve insan kaynağını kullanarak emniyetli ve verimli (efficient) uçuş operasyonun sağlanması olarak tanımlanmaktadır (Flin vd, 2002: 69). EKY kapsamında yönetilmeye çalışılan en önemli kaynak insan kaynağıdır. CRM insan - insan etkileşimini emniyet açısından olumlu yönde 
geliştirmeye odaklanmakta, teknik olmayan becerilerini geliștirmeyi amaçlamaktadır. CRM kapsamında; iletişim, takım çalışması, liderlik, durumsal farkındalık, karar verme, çatışma yönetimi, stres yönetimi gibi konular ele alınmaktadır.

Yaşın ilerlemesi ile birlikte kişilik özelliklerinin değiştirilmesi oldukça güçtür. Bununla birlikte tutumların değiştirilmesi mümkündür. Bu durumda pilotların uçuş emniyetini etkileyebilecek konularda tutumlarının değiştirilmesi onların davranışlarını da etkileyecektir.

EKY programlarının en önemli amaçlarından birisi pilotlara emniyet açısından olumlu tutumlar kazandırmaya çalışmaktır. Helmreich ve Foushee (1993) tarafından geliştirilen girdi-süreç-çıktı modelinde kokpit içerisinde pilotların davranışları üzerinde hangi unsurların etkili olduğu ifade edilmiştir. Pilotların davranışlarını etkileyen faktörler arasında bireysel tutumlar fiziksel şartlar, düzenleyici çevrenin (regulatory environment) yanı sıra meslek kültürü, örgütsel kültür ve ulusal kültürel etkenlerinde sıralandığı görülmektedir (Helmreich- Merritt, 2001:7).

Kokpitte yapılan hataların analiz edilmesi ile birlikte kokpitin kültürden bağımsız bir çalışma ortamı olmadığı görülmüştür. Kültür, tutum ve değerleri şekillendirerek, açık bir şekilde davranışlar üzerinde etkili olmaktadır. Bu nedenle kültür, pilotların uçuş emniyeti üzerinde etkili olabilecek davranışları üzerinde oldukça önemli bir etkiye sahiptir (Helmreich, 1999: 1). Sonuç olarak EKY eğitimlerinin etkinliği bireyin davranışları üzerinde etkili olan kültürel özelliklerden etkilenmektedir.

EKY'yi öncelikle uygulandığg yerdeki ulusal kültür özellikleri etkilemektedir. Diğer yandan EKY'nin etkinliğini meslek ve örgüt kültürleri de etkilemektedir. Appelbaum ve Fewster (2004: 3).de EKY için oldukça önemli olan kokpit içindeki iletişimin ulusal kültür içerisindeki farklılıklar ve mesleki alt kültürlerden (hata trafik kontrolörleri, havaaracı bakım teknisyenleri, kabin ekibi ve pilotların sahip oldukları meslek kültürü) ciddi şekilde etkilendiğini belirtmektedirler.

Kültürel özellikler ve kokpitteki davranışlar arasında açık bir ilişki bulunmaktadır. EKY programlarının amaçlarına ulaşabilmesi bu programların ekiplerin kültürel değerleri ile ne kadar uyumlu olup olmadığına bağlıdır. Örneğin bireycilik-kolektivizm boyutundaki değerler kokpit içerisindeki grup atmosferini, bireylerin grup içerisindeki uyum ve ilişkileri ile ilgili tutumlarını etkilemektedir. Güç mesafesi ise; nispeten acemi veya ast konumundaki pilotların kaptan pilotla ilişkilerini, kokpit içerisindeki bilgi paylaşımını ve astların kritik bilgileri kaptana söyleme konusunda kendilerini ne kadar rahat hissettiklerini belirlemektedir. Diğer yandan, güç mesafesi otokratik liderlik tipinden demokratik liderlik tipine doğru olan bir skalada liderlik stillerinin şekillenmesinde etkili olmaktadır. Yüksek güç mesafesi değerlerine sahip ülkelerde otokratik liderlik tarzları daha çok görülürken düşük güç mesafesine sahip kültürlerde astlarından bilgi talep eden ve fikirlerini onlarla paylaşan "danışman liderlik" şekli daha yaygın bir şekilde görülmektedir. Belirsizlikten kaçınma boyutu ise, ekip üyelerinin kurallara ve Standart Isşletim Uygulamalarına (Standart Operation Procedures- SOP) uyum derecelerini belirlemektedir (Helmreich, 2000: 136).

\subsection{Teksas Üniversistesi'nin Ekip Kaynak Yö- netimi Ve Kültür Araştırmalar}

1992 y1lında Helmreich ve Merritt (2001: 64), Hofstede tarafından IBM araştırmaları çerçevesinde ülkelerin kültürel farklılıklarını ortaya koymaya yönelik olarak kullandığı veri toplama aracını ve ölçekleri hava taşımacılığına uyarlayarak farklı ülkelerden pilotların kültürel özelliklerini tespit etmeye çalışmıştır. Helmreich ve Merritt tarafından soru formu şeklinde geliştirilen ve farklı ölçekleri kapsayan ankete Uçuş Yönetimi Tutumları AnketiUYTA (Flight Management Attitudes-FMAQ) adı verilmiştir. Bu kapsamda, 1993-1997 yılları arasında FMAQ ile 23 farklı ülkeden 36 havayolu işletmesinde çalışan 15000 pilottan veri toplanmıştır (Helmreich-Merritt, 2001: 42). 
Teksas Üniversitesi tarafından yapılan araștırmalarda farklı ülkelerden alınan örneklemlerin Hofstede boyutlarında sahip oldukları indeks değerleri tespit edilmiştir. Ulusal kültür boyutlarının yanı sıra Helmreich ve Merritt (2001: 34), tüm pilotların paylaştıkları ortak değerlerin oluşturduğu meslek kültürünün özelliklerini ortaya koymuşlardır. Helmreich ve Merritt (2001:56), farklı kültürel özelliklere sahip olan pilotların; otorite, liderlik, stresin algılanması, emir verme, iletişim gibi EKY becerileri ile ilgili tutumlarını da tespit etmişlerdir. Ulusal kültür ve meslek kültürünün EKY becerilerine olan etkilerini belirleyen Helmreich ve Merritt (2001: 107), örgütsel kültür öğelerinin de ekip üyelerinin tutum ve davranışları üzerinde etkili olduğunu ortaya koymuşlardır.

Goode (1957), meslek kültürünün bireylere ortak bir kimlik veren bir aidiyet duygusu ile birbirlerine bağladığını belirtmektedir. Normlar ve değerler meslek grubu içerisindeki k1demli kişiler tarafından yeni girenlere aktarılmaktadır. Meslek grupları mensuplarını korurken sosyal kontrolü de sağlar. Ticari havacılığın da son derece karmaşık bir sistem olması, risk unsurunun yüksek olması, hem ulusal hem de uluslararası düzeyde kontrol ediliyor olması güçlü bir meslek kültürünün gelişmesine neden olmuştur (Helmreich-Merritt, 2001: 30).

Güçlü bir meslek kültürüne sahip olan mesleklerde, bireylerin yaptıkları işe oldukça fazla değer verdikleri görülmektedir. Helmreich ve Merritt (2001: 31) "işimi seviyorum" ifadesine cevaplayıcıların \%75'i "kesinlikle katılıyorum", \%17'si ise "katılıyorum" cevabını verirlerken, sadece $\% 4,5$ oraninda "katılmiyorum" cevabı alınmıştır. Bu sonuçlara göre dünyadaki pilotların işlerini oldukça fazla sevmelerinin meslek kültürünün bir sonucu olarak ortaya çıtı̆̆g düşünülmektedir (Helmreich-Merritt, 2001: 30). Fakat pilotluk mesleğinin mensubu olmak nedeniyle hissedilen gurur, kendini beğenmişlik ve aşırı maço tutumlara dönüșebilmektedir. Bu durumda diğerlerinin fikirleri dinlenmeyecek ve alternatif yollar değerlendirilmeyecektir. Kişilerin limitlerini doğru olarak algılayamamaları stan- dart işletim prosedürlerini hiçe saymalarına ve uçuşun devam ettirilebilmesi için tehlikeli durumların denenmesine neden olabilmektedir (Helmreich-Merritt, 2001: 34). Diğer yandan, meslek kültürü pilotların kendileri ile ilgili yanlış algılamalara sahip olmalarına neden olmaktadır. Meslek kültürünün etkisi ile pilotlar yorgunluk gibi faktörleri doğru algilayamayabilmektedirler. Ayrıca, pilotlar acil durumlarda da karar verme becerilerinin hiçbir şekilde olumsuz yönde etkilenmediğini ve gerçek bir profesyonelin kokpite girdiğinde tüm problemlerini arkada birakabileceğini düşünmektedirler. Bu durum, hataların yönetilmesini zorlaştırmaktadır (HelmreichWilhelm, vd., 2001: 4).

\subsection{EKY ve Kültür İlişkisini İnceleyen Diğer Araştırmalar}

İnsan faktörlerine ilişkin Gümüş (1998) tarafından yapılan araştırma silah üreten bir fabrikada üretim sorunlarının kullanılan teknoloji ve donanımdan çok insan hatalarından kaynaklandığ1 tespit edilmiştir (Gümüş, 1998: 40).. Diğger yandan, Türkiye'de insan-makine ve insan-çevre etkileşimleri ile ilgili birçok araştırma bulunmaktadır. Kıraç (2005: tarafından yapılan araştırmada büro hizmetlerinde ergonomi ve ergonominin memurların verimliliklerine etkisi tespit edilmeye çalışılmıştır. Yapılan bu çalışma sonucunda çalışanların fiziksel çevreden etkilendikleri ortaya çıkmıştır (Gümüş, 1998:i).

EKY programları Türk havayolu işletmeleri tarafından yoğun bir şekilde uygulanmasına rağmen, bu konudaki akademik araștırmalar oldukça azdır. Elbaşı tarafından 2003 yılında yapılan araştırmada farklı havayolu işletmelerinde emniyet kültürüne ilişkin algılamaların farklı olduğu ortaya konmuştur (Elbaş1, 2003: 142). Elbaşı (2003: 153)'nın araştırmasında elde ettiği diğer bir bulgu, örgüt içerisindeki pilotların sahip oldukları hiyerarşik konuma göre birbirlerine olan tutumlarınin farklılık göstermesidir.

Diğer yandan Elbaşı (2003:153), alt kültürel farklılıkların emir ve komuta ile ilgili farklı tutumların oluşmasında etkili olduğunu belirtmektedir. Bu farklılıklar asker ve sivil kö- 
kenli pilotlar arasında da görülmektedir. Elbaşı (2003: 157) yaptığı araştırmada Türk pilotların liderlik tercihlerini de ortaya koymuştur. Araştırma sonuçları Türk pilotların en çok demokratik lider tarzı ile çalışmak istediklerini ortaya koymaktadır. Diğer yandan, yardımcı pilotların uçuş emniyeti ve hataların ikaz edilmesi söz konusu olduğunda kendilerini yeterince özgür hissetmedikleri ortaya çıkmıştır. Diğer yandan Elbaşı (2003: 158), yardımcı pilotların demokratik özelliklere sahip olan kaptan pilotlarla uçmak istemelerine rağmen, kaptan pilot olduklarında daha otokratik liderlik tarzı ortaya koyduklarını belirtmektedir. Ayrıca asker kökenli pilotların askeri kurumlarda edindikleri liderlik tarzını işlerine yansıttıklarını görülmüştür. Askeri pilotlar lider olmak üzere yetiştirilmektedirler ancak eğitimleri boyunca kendilerinden lider oluncaya kadar liderlerine mutlak itaat beklenmektedir. Lider olduktan sonra da durum fazla değişmemekte, üste sayg1 ve asttan itaat bekleme tutumu devam ettirilir. Asker kökenli pilotlarda görülen otoriter liderlik tiplemesi, sivil havacılığa taşınmakta ve bu nedenle otoriter liderlik tarzına sıkça rastlanmaktadır (Elbaş1, 2003: 154).

\section{ARAŞTIRMANIN AMACI VE YÖNTEMI}

Daha önce de açıklandığ 1 gibi Hofstede yaptığ1 araştırmada ulusal kültür özelliklerinin dört ayrı boyutta farklılıklar gösterdiğini bulmuştur. Başka bir deyişle farklı ulusların farklı kültürel özellikleri bulunmaktadır.

Kültürel özellikler pilotların değer ve tutumlarını dolayısıyla davranışlarını etkiliyorsa EKY programlarının her ulusal kültür ortamında aynı başarıyı elde etmesi mümkün değildir (Helmreich, basım aşamasında:2). Ulusal kültür farklılıkları EKY eğitimlerinin etkinliğini önemli bir ölçüde etkilemektedir. Oysa uçuş emniyetin artırılabilmesi için EKY programlarından çok şey beklenmektedir. Bu kapsamda batı kültürlerinde tasarlanan EKY programları aynen alınıp kullanılmaktadır. EKY'nin emniyeti artıracağı düşünülmekte fakat bu şekilde artıramayacağı gözden kaçmaktadır. Bu nedenle EKY eğitimleri, ulusal kültür özelliklerine göre şekillendirilmelidir.
Ulusal farklılıkları göz önünde bulundurmadan tasarlanan EKY eğitimleri ekip üyelerinin; iletişim, takım çalışması, liderlik, karar verme, durumsal farkındalık, çatışma ve stres yönetimi gibi teknik olmayan becerilerinin istenen düzeyde geliştirilmesini sağlayamaz. Bu durum ise, uçuş emniyetini ciddi bir biçimde tehlikeye atabilir.

Bu araştırmada kapsamında öncelikle bazı Türk Havayolu işletmelerinde rasgele seçilen pilotlarla biçimsel olmayan görüşme yöntemi ile bir ön araştırma yapılmıştır. Bu ön araştırmanın amacı Türkiye'deki EKY eğitimleri yapilırken ulusal kültür özelliklerinin ne derece dikkate alındığının araştırılmasıdır.

Bu ön araştırmanın sonuçlarından elde edilen verilere göre Türkiye'de EKY eğitimleri, kültürel farklılıklar göz önüne bulundurulmadan yapılmaktadır. Ayrıca pek çok havayolu işletmesinin EKY'nin istenen amaçlara ulaşıp ulaşmadığını ölçmediği görülmektedir. Buradaki esas tehlike ise, havayolu işletmelerinin EKY eğitimlerini verdikten sonra pilotlara emniyet açısından olumlu tutumlar kazandırıldığını ve teknik olmayan becerilerin geliştirildiğini düşünmeleridir. Buna ek olarak, ön araştırma sonucunda elde edilen izlenimler Türkiye'deki havayolu işletmelerinden bazılarının sadece düzenlemelerin gereğini yerine getirmek için EKY eğitimleri düzenlediklerini göstermektedir.

Helmreich ve Merritt (2001) tarafından 1993-1997 yılları arasında yapılan Teksas Üniversitesi Araştırmalarında Türkiye yer almamaktadır. Kültürel boyutlar açısından Türk pilotların durumu bilinmemekte ve bu durum araştırma probleminin önemli bir bölümünü oluşturmaktadır. Bu nedenle, Hofstede (2000) tarafından 20 yıl önce yapılan araştırmalarda Türkiye ile ilgili elde edilen kültürel değerlerin pilotlarda ne şekilde olduğunu belirlemek oldukça önemlidir. Diğer yandan Teksas Üniversitesi tarafından yapılan araştırmalar, tüm dünyadaki pilotların meslek kültüründen kaynaklanan birtakım ortak tutumlara sahip olduğunu göstermektedir. Bu ortak tutumların Türk pilotlar tarafından ne kadar benimsendiğini belirlemek diğer önemli bir araştırma konusudur. 
Bu anlamda ulusal kültür farklılıkları, Türk havayolu pilotlarının Hofstede kültür boyutları açısından yerlerinin araştırılması ve EKY'nin ulusal kültür özelliklerine göre tasarlanması önemli bir araştırma problemi olarak ortaya çıkmaktadır.

\subsection{Araştırmanın Amacı}

Açıklanan araştırma problemi kapsamında bu çalışmanın amacı Türkiye'de kullanılan EKY eğitimlerinin Türk Ulusal Kültürüne uygun hale getirilmesinde kullanilacak verileri sağlamaktır. Bu verileri sağlamak için Türk pilotların Hofstede tarafından belirlenen kültürel boyutlardaki yerleri tespit edilecektir. Diğer yandan, Türk pilotların Helmreich ve Merritt (2001) tarafından belirlenen tüm dünyadaki pilotların sahip oldukları ortak tutumlar konusundaki durumları araştırılacaktır. Tanımlanan araştırma problemi kapsaminda bu amaca ulaşabilmek için 3 adet araştırma sorusu tespit edilmiştir. Bunlar:

1.Türkiye'deki tüm pilotlar dikkate alınd1ğında Türk Pilotların Hofstede'in ulusal kültür boyutlarındaki durumları nelerdir?

2.Türk Pilotların Hofstede'in ulusal kültür boyutlarındaki durumları Teksas Üniversitesi tarafından aynı boyutlarda ve aynı yöntemle elde edilen 22 farklı ülke pilotlarının siralamasında nerede yer almaktadir?

3.Teksas Üniversitesi tarafından yapılan çalışmalarda saptanan ve meslek kültürünün etkisi ile dünya genelindeki pilotlarda ortak olarak ortaya çıkan değerler açısından Türk pilotların durumu nedir?

$\mathrm{Bu}$ araştırmanın temel olarak kapsamını havayolu taşımacılığı faaliyetlerinde görev alan T.C. vatandaşı kaptan ve yardımcı pilotlar oluşturmaktadır. Türk tescilli tarifeli ve tarifesiz seferler düzenleyen havayolu işletmelerinin pilotları ve uçuş mühendisleri kapsam dâhilindedir.

\subsection{Araștırmanın Evreni}

Bu araştırmanın evreni Türkiye'de faaliyet gösteren havayolu işletmelerinin havaaraçla- rında çalışan ve Türkiye Cumhuriyeti vatandaşı olan; pilot, yardımcı pilot (first officer) ve uçuş mühendisleridir (second officer). Türkiye Havayolu İşletmeleri Pilotları Derneği (Turkish Airline Pilots AssociationTALPA)'dan elde edilen bilgilere göre Türkiye'de ticari havayolu işletmelerinde çalışan pilotların tamamına yakını TALPA'ya üyedir. Yine TALPA'dan elde edilen bilgilere göre 2005 Haziran ayı itibarı ile bu derneğe üye 1600 adet pilot bulunmaktadır. Bu evrenden "basit tesadüfi örnekleme" yolu ile bir örneklem alınmıştır. Araştırma kapsamında 350 adet soru formu pilotlara dağıtılmıştır. Geri dönüş oranı $\% 62,8$ olmuş, geri dönen toplam 220 soru formundan 211 adeti değerlendirilmiştir.

\subsection{Veri Toplama Aracı}

$\mathrm{Bu}$ araştırmada, veri toplama aracı olarak tutum tespit etmeye yarayan bir soru formu kullanılmıştır. Uçuş Yönetim Tutumları Anketi (Flight Management Attitudes Questionnaire-FMAQ) adlı soru formu Helmreich ve Merritt (2001) tarafından geliştirilmiştir. FMAQ Hofstede (2000)'in geliştirdiği soru formunun havayolu taşımacılığında görev alan pilot, yardımcı pilot ve uçuş mühendislerine uyarlanmış halidir. FMAQ ABD'de ve uluslararası alanda uygulanmak üzere iki farklı biçimde düzenlenmiştir. $\mathrm{Bu}$ çalışmada FMAQ'ın uluslararası versiyonu kullanılmıştır. Örgüt kültürü bu çalışmanın kapsamında olmadığ 1 için FMAQ' taki buna ilişkin 44 adet ifade çıkarılmıştır.

FMAQ İngilizceden Türkçeye, ana dili Türkçe olan fakat yıllarca ABD'de pilot olarak çalışmış bir kişi ve mesleki yabancı dil bilgisine sahip diğer araştırmacılar tarafından çevrilmiştir. Ayrıca FMAQ'ın Türkçe'ye çevrilmiş hali, farklı havayolu işletmelerinden 15 kaptan pilot ve yardımcı pilota dağıtılarak anlaşılmayan sorular olup olmadiğ1 tespit edilmiştir. Ön test aşamasından sonra soru formunun son hali elde edilmiştir.

Teksas Üniversitesi'ndeki bilim adamları tarafından geliştirilen UYTA'dan elde edilen sonuçlar ile Hofstede tarafından elde edilen değerler "güç mesafesi", "belirsizlikten ka- 
çınma" ve "kolektivizm/bireycilik" boyutlarında benzeşim göstermiştir. Bu nedenle bu çalışmada da sözü edilen 3 boyut dikkate alınmiştır. Bu çalışmada anketin güvenirliği Crombach-Alpha yöntemi ile hesaplanmış ve anketin toplam iç güvenirlik katsayısı 0,79 olarak bulunmuştur.

Araştırmada kullanılan soru formunda demografik sorular dişında 67 adet soru bulunmaktadır. Pilotların tutumları, 5'li Likert tipi ölçekle belirlenmeye çalışılmıştır.

FMAQ'in uygulanabilmesi için öncelikle havayolu işletmelerinden izin alınmıştır. Sonra havayolu işletmelerinin; uçuş işletme, eğitim faaliyetleri ve EKY ile ilgili üst düzey yöneticileri çalışmanın amaçları ve soru formu hakkında bilgilendirilmiştir. Ayrıca Türkiye Havayolu İşletmeleri Pilotları Derneği'nin (Turkish Airline Pilots Association - TALPA) yöneticileri de bilgilendirilerek soru formlar1nın uygulanmasında önemli katkıları sağlanmiştır. Soru formları pilotlara elden dağıtılmıs, işletme isimlerinin kesinlikle talep edilmediği vurgulanarak soru formunun doldurulması ile ilgili ön yargıları ortadan kald1rılmıştır. Diğger yanda, soru formları TALPA internet sayfasina konularak doldurulup elektronik posta ile gönderilmesi sağlanmıştır. Verilerin toplanması 2005 yılı Temmuz-Ekim ayları arasında gerçekleşmiştir.

Diğer yandan veri toplama sürecinde, soru formunun yanı sira, EKY'den sorumlu olanlar ve diğer pilotlar ile yapılandırılmamış görüşmeler yapılmıştır. Bu görüşmeler ile son derece değerli olduğu düşünülen bilgiler elde edilmiştir.

\subsection{Verilerin Çözümlenmesi}

Toplanan verilerin çözümlenmesinde "betimsel" çözümleme yöntemleri kullanılmıştır. Türk pilotların Hofstede kültür boyutlarındaki özellikleri ve meslek kültürü açısından benzerliklerin tespit edilmesinde tanımlayıcı çözümleme yöntemlerinden; ortalamalar, frekanslar ve yüzde olarak oranlar kullanılmış, ortalama değerlere göre sıralamalar yapılmıştır. Ortalamaların hesaplanabilmesi için 5'li Likert tipi tutum ölçeğindeki ifadelerin seçimlik cevaplarına 1, 2, 3, 4 ve 5 değerleri atanmıştır.
Ulusal kültür boyutlarında Hofstede (2000) ve Teksas Üniversitesi çalışmalarında olduğu gibi index hesaplanmıştır. Sözü edilen indeks hesaplanması Hofstede tarafından geliştirilmiștir. Helmreich ve Merritt (2001), Teksas Üniversitesi Araştırmaları kapsamında Hofstede tarafından geliștirilmiş indeksleri havayolu taşımacılığ 1 sektörüne uyarlamışlardır. Bu araștırmada ise, Türk pilotların "güç mesafesi", "belirsizlikten kaçınma" ve "bireycilik" indekslerinin belirlenmesinde Helmreich ve Merritt tarafından geliştirilen formüller kullanılmıştır.

İndekslerin yanı sıra, bazı sorularda Türk pilotların katılım düzeylerini belirlemek için frekans analizi, ortalama, standart sapma gibi temel istatistikî göstergeler de değerlendirilmiştir.

\section{BULGULAR VE TARTIŞMA}

\subsection{Araștırmaya Katılan Pilotların Genel Özellikleri}

Soru formlarına cevap veren pilotlar daha önce çalıştıkları kurumlara göre değerlendirildiklerinde bu pilotların 148'inin T.S.K. kökenli ve 63'ünün de sivil kökenli olduğu görülmektedir. Diğer yandan, araştırmaya katılan pilotların 163'ü hat, 32'si öğretmen, 8'i kontrol ve diğer 8 'i ise aynı zamanda yönetici olan pilotlardır. Soru formuna cevap veren pilotların 131'i kaptan pilot, 74'ü yardımcı pilot ve 6's1 ise uçuş mühendisidir. Araștırmada yer alan pilotların eğitim düzeyleri, beklendiği gibi oldukça yüksektir. 211 pilotun 12'si yüksek lisans ya da doktora, 198'i lisans ve 1'i önlisans düzeyinde eğitim almıştır. T.S.K. kökenli pilotların tamamı, pilotaj eğitimlerini T.S.K bünyesinde alırken, sivil kökenli pilotların 28'i Anadolu Üniversitesi Sivil Havacılık Yüksekokulu'nda, 20'si yurtdışında, 10'u Türkiye'deki özel bir uçuş okulunda ve 5'i ise Türk Hava Kurumunda pilotaj eğitimini almişlardır. Diğger yandan, araştırmada yer alan pilotların 100'ü 45 yaş üzerinde yer alırken 111 ' $i$ ise 45 yaş altındadır.

\subsection{Türk Pilotlarn Ulusal Kültür Boyutlarn}

\subsubsection{Güç Mesafesi Boyutu}


Güç mesafesi indeksinin belirlenmesinde, birlikte çalışılan ile ideal (istenen) liderlik tarzlarının saptanmaktadır. Elde edilen sonuçlara göre Türk pilotların \%63,5'i hâlihazırda daha çok otokratik liderlik tipi ile çalıştıklarını ifade etmişlerdir. Bu durum, Türk pilotlarının yüksek güç mesafesi değerlerine sahip olduğu ile ilgili önemli bir bulgudur. Buna karşın, pilotların önemli bir bölümü demokratik lider tipi ile çalışmayı tercih ettiklerini belirtmişlerdir. Türk pilotların \%56,4'üün ideal lider olarak danışman (consultative) lider tarzı ile çalışmayı tercih etmelerinin güç mesafesini azaltmaya yönelik bir çaba olduğu düşünülmektedir.

Otokratik liderlik tipi, kokpit içerisinde fikirlerin rahatça ifade edilmesini engelleyebilmektedir. Araştırma sirasında yapilan görüşmelerde yardımcı pilotların genellikle uçuş başlamadan önce kaptan pilotun liderlik tipi ile ilgili bilgi edinerek, uçuş sırasında buna uygun davranışlar sergilemeye çalıştıkları saptanmıştır. Bu durum, pilotların otokratik liderlerle çalışırken, gerçek tutum ve davranışlarını sergilemekten çekindiklerini göstermekte ve EKY'nin temelini oluşturan "açık iletişim" için olumsuz bir ortam oluşturmaktadir.

Liderlik ile ilgili değerlendirmelerin yanı sıra, "çalışma ortamınızda astlar, hangi sıklıkta üstleri ile aynı fikirde olmadıklarını söylemeye çekinirler?" ifadesine verilen cevaplar da güç mesafesinin belirlenmesinde diğer önemli bir göstergedir. Türk pilotlarm büyük bir kısmı bu ifadeye çok sık, sık ve bazen $(\% 72,4)$ cevabını vermişlerdir. Bu durum, Türk pilotların uçuş sırasında fikirlerini açıkça belirtmekte çekingen davrandıklarını göstermektedir.

Liderlik ve fikirlerini belirtebilme konusunda elde edilen verilere göre hesaplanan "Türk Pilotların Güç Mesafesi İndeksi-PDI" “96" olarak belirlenmiștir. Hofstede (2000)'in çalışmasında Türkiye'nin güç mesafesi indeksi "66" olarak hesaplanmiştır. Bu durum Helmreich ve Merritt (2001)'in bulguları ile paralellik göstermektedir. Helmreich ve Merritt, pilotların sahip oldukları güç mesafesi değerlerinin pilotluk mesleğine ilişkin kültürel özellikler nedeniyle Hofstede tarafından elde edilen güç mesafesi değerlerinden daha yüksek olduğunu belirtmektedirler.

Helmreich ve Merritt (2001), liderlik ve fikir belirtebilme ile ilgili ifadelere ek olarak belirledikleri diğer tutum ifadeleri ile pilotların güç mesafelerini belirlemişlerdir. Elde edilen verilerin çözümlenmesinde "Kesinlikle Katıliyorum" ve "Katılıyorum" ile "Kesinlikle Katılmiyorum" ve "Katılmiyorum" cevaplarının sıklıkları birlikte toplanarak verilmiştir. Ayrıca her bir tutum ile ilgili verilen cevapların ortalamaları hesaplanmıştır. Yüksek güç mesafesine işaret eden tutum ifadelerine dikkat çekmek amaciyla ortalama değeri 3'ün üstünde ve altında olanlar tespit edilmiş ve Tablo-1'de verilmiştir. Tutum ölçeğinin 5'li Likert olması nedeniyle ortalama değerlerin yorumlanmasında orta nokta değeri olan 3 referans nokta olarak seçilmiştir.

Diğer yandan, pilotların otomasyonla ilgili ifadelere verdikleri cevaplar da güç mesafesi ile ilgili önemli bir ipucu niteliğindedir. Helmreich ve Merritt (2001: 98), uçuş sırasında otomasyonu kullanilmasinin tercih edilmesini yüksek güç mesafesi ile ilişsilendirmektedir. Güç mesafesinin yüksek olduğu kültürlerde pilotlar, kokpit içerisindeki otomasyonu havayolu yönetimin satın aldığı göreceli olarak kendilerinden daha kıdemli ve bu nedenle sorgulanmaması gereken bir ekip üyesi olarak değerlendirmektedirler (Helmreich ve Merritt 2001: 100).

Tablo-2'den de anlaşıldığ 1 üzere Türk pilotlar uçuş sırasında yoğun bir şekilde otomasyonun kullanımını tercih ettiklerini ortaya koymaktadır. Türk pilotlar otomatik uçaklarla uçmayı, uçuş sırasına mümkün olduğunca otomasyonu kullanmayı ve önemli bir oranda otomasyonun sağladığı araçları uçuş sırasında kullanmayı tercih etmektedir. Ayrıca Türk pilotlar, olağan dişı durumlarda da otomasyonun sunduğu bilgileri kullanmayı tercih etmektedir. Bu bulgular Türk pilotların otomasyona aşırı güven duydukları ve otomasyonu kokpit içerisinde nispeten kendilerinden daha ehil bir ekip üyesi olarak görüyor olabilecekleri ile ilgili önemli bir ipucudur. 


\section{Tablo 1}

\section{Güç Mesafesi}

\begin{tabular}{|c|c|c|c|c|}
\hline İfadeler & $\begin{array}{l}\text { Kesinlikle } \\
\text { Katılyorum } \\
\text { ve } \\
\text { Katılıorum } \\
\text { Oran (\%) }\end{array}$ & $\begin{array}{l}\text { Kararsizim } \\
\text { Oran } \\
(\%)\end{array}$ & $\begin{array}{c}\text { Kesinlikle } \\
\text { Katılmıyorum ve } \\
\text { Katılmıyorum } \\
\text { Oran (\%) }\end{array}$ & Ortalama \\
\hline $\begin{array}{l}\text { Görevimi yerine getirirken } \\
\text { performansımı etkileyen konularla } \\
\text { ilgili olarak bana danışılmasını beklerim. }\end{array}$ & 90,9 & 2,4 & 6,7 & 1,23 \\
\hline $\begin{array}{l}\text { Kaptan acil ve olağandıșı durumlarda } \\
\text { fiziksel kontrolü ele almalı ve } \\
\text { uçağı uçurmalıdır. }\end{array}$ & 73 & 3,3 & 23,7 & 3,99 \\
\hline $\begin{array}{l}\text { Üst düzey çalıșanlar diğer personele } \\
\text { göre daha fazla ücret ve } \\
\text { ayrıcalıkları hak ederler. }\end{array}$ & 90,9 & 9,0 & 11,4 & 3,83 \\
\hline $\begin{array}{l}\text { Uçuș sırasında meydana gelebilecek olağandışı } \\
\text { durumlarda üstlerimin bana yapmam gerekenler } \\
\text { konusunda söylediklerine güvenirim. }\end{array}$ & 58,7 & 19,9 & 21,4 & 3,40 \\
\hline $\begin{array}{l}\text { Uçuș kabininin (flight deck) bașarılı } \\
\text { bir șekilde idare edilmesi en bașta } \\
\text { kaptanın uçuș becerisine bağlıdır. }\end{array}$ & 50,2 & 4,7 & 45,1 & 3,18 \\
\hline $\begin{array}{l}\text { Uçuș emniyetini tehlikeye atmadıkları } \\
\text { sürece, diğer ekip üyeleri kaptanın } \\
\text { hareketlerini sorgulamamalıdır. }\end{array}$ & 40,7 & 7,7 & 51,6 & 2,87 \\
\hline $\begin{array}{l}\text { Kaptanın tamamen inkapasitasyon yaşadığı } \\
\text { zamanlar hariç yardımcı pilot asla } \\
\text { havaaracının kontrolünü ele almamalıdır. }\end{array}$ & 23,2 & 3,8 & 73 & 2,23 \\
\hline $\begin{array}{l}\text { Diğer ekip üyelerinin fikir belirtmelerini } \\
\text { teșvik eden kaptanlar zayıf liderlerdir. }\end{array}$ & 4,3 & 0,5 & 95,2 & 1,37 \\
\hline $\begin{array}{l}\text { Ekip içerisindeki astlar (genç ve tecrübesiz pilotlar) } \\
\text { kaptanın veya daha kıdemli ekip üyelerinin } \\
\text { kararlarını sorgulamamalıdır. }\end{array}$ & 14,2 & 5,7 & 80,1 & 1,96 \\
\hline
\end{tabular}

\subsubsection{Belirsizlikten Kacınma Boyutu}

Bu araştırmada "belirsizlikten kaçınma indeksini" hesaplamak için "işte kendinizi hangi sıklıkta sinirli veya gergin hissedersiniz?" ve "uçuş ekibi, işletme yararına olduğunu düşünse bile, işletmenin uçuşa ilişkin kuralların ihlal etmemelidir" ifadelerine verilen cevapların ortalamaları kullanılmıştır.

Türk pilotların "işte kendinizi hangi sıklikta sinirli veya gergin hissedersiniz?" ifadesine verdikleri cevapların ortalaması 3 'ün üzerindedir. Tablo-3'den de görüldüğg̈ gibi cevaplar genelde bazen ve nadiren seçeneklerinde toplanmıştır. Bu durum, Türk pilotların iş yerinde nadiren stres yaşadıklarını göstermektedir.
Belirsizlikten kaçınma indeksini belirlemede kullanılan "uçuş ekibi, işletme yararına olduğunu düşünse bile, işletmenin uçuşa ilişkin kuralların ihlal etmemelidir" ifadesinde elde edilen sonuçlar ise, Türk pilotların büyük bir çoğunluğunun $(\% 88,6)$ işletme lehine olsa bile kuralları ihlal etme konusunda çok çekingen davrandıklarını göstermektedir. $\mathrm{Bu}$ durum, Türk pilotların yüksek belirsizlikten kaçınmanın etkisi ile çok fazla kural odaklı oldukları şeklinde yorumlanmıştır.

Türk pilotların belirsizlikten kaçınma indeksi işyerinde nadiren stres yaşadıklarını belirtmelerine rağmen "95" olarak hesaplanmıştır. Hofstede (2000: 151) ise, Türkiye'nin belirsizlikten kaçınma indeksini " 85 " olarak saptamıştır. Helmreich ve Merritt 


\section{Tablo 2}

Otomasyon

\begin{tabular}{|l|c|}
\hline \multicolumn{1}{|c|}{ İfadeler } & $\begin{array}{c}\text { Katılıyorum } \\
\text { ve } \\
\text { Kesinlikle Katılıyorum } \\
\text { (\%) }\end{array}$ \\
\hline $\begin{array}{l}\text { Otomatik özellikleri olan uçakla } \\
\text { uçmayı tercih ederim }\end{array}$ & 94,3 \\
\hline $\begin{array}{l}\text { Etkili bir kokpit ekibi her zaman } \\
\text { otomasyonun sağladığı araçları kullanır. }\end{array}$ & 77,8 \\
\hline Daha fazla otomasyon daha iyidir & 63,0 \\
\hline $\begin{array}{l}\text { Uçuș sırasında mümkün olduğu kadar } \\
\text { çok otomasyon kullanmaya çalıșırım. }\end{array}$ & 86,2 \\
\hline $\begin{array}{l}\text { Olağan dıșı durumlarda ihtiyacım olan bilgiye } \\
\text { uçuș yönetim bilgisayarından hızlıca ulașabilirim. }\end{array}$ & 89,1 \\
\hline
\end{tabular}

(2001: 249) tarafından pilotlar üzerinde yapılan araştırmada en düşük değer 23 (Danimarka) ve en yüksek değer ise, 112 (G.Kıbrıs) olduğu saptanmıştır. Bu değerlerle kıyaslandığında Türk pilotların yüksek belirsizlikten kaçınma özelliklerine sahip oldukları söylenebilir.

Diğer yandan, yazılı kurallar konusundaki tutumlar da belirsizlikten kaçınma ile ilgili önemli gösterge niteliğindedir. Türk pilotların \%78'i "yazılı prosedürler bütün uçuş durumlarında gereklidir" ifadesine "katılıyorum" ve "kesinlikle katılıyorum" ce- vab1 vermişlerdir. Bu durum, Türk pilotların belirsizlikten kaçınma değerlerinin yüksek olduğu ile ilgili bir diğer bulgudur.

Helmreich ve Merritt (2001: 72), belirsizlikten kaçınma boyutu ile ilgili araştırmalarında FMAQ içerisinde yer alan "iş değerleri" ile ilgili ifadelerden de faydalanmışlardır. Türk pilotların iş değeri ifadelerine verdikleri cevaplarda yüksek ortalamalara sahip olmaları belirsizlikten kaçınma eğilimi ile ilgili daha önce elde edilen bulguları doğrular niteliktedir. Türk pilotların söz konusu değerleri önemli bulmaları, iș ile ilgili beklenmeyen

Tablo 3

Belirsizlikten Kaçınma

\begin{tabular}{|c|c|c|c|c|c|c|c|c|c|c|}
\hline & \multicolumn{5}{|c|}{$\begin{array}{l}\text { İște kendinizi hangi sıklıkta sinirli } \\
\text { veya gergin hissedersiniz? }\end{array}$} & \multicolumn{5}{|c|}{$\begin{array}{l}\text { Uçuș ekibi, ișletme yararına olduğunu } \\
\text { düșünse bile, ișletmenin uçușa iliş̧kin } \\
\text { kurallarını ihlal etmemelidir. }\end{array}$} \\
\hline & 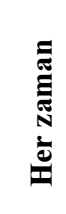 & ל⿺辶一 & 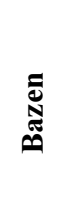 & : & 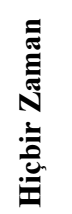 & 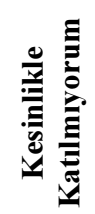 & 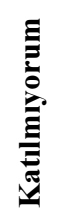 & 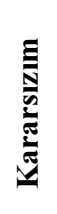 & 豆 & 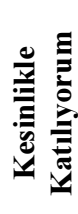 \\
\hline Sıklık & 2 & 1 & 59 & 140 & 9 & 8 & 12 & 4 & 64 & 123 \\
\hline Ortalama & \multicolumn{5}{|c|}{3,73} & \multicolumn{5}{|c|}{4,34} \\
\hline
\end{tabular}




\section{Tablo 4}

Belirsizlikten Kaçınma Boyutu İş Değerleri

\begin{tabular}{|l|c|c|c|}
\hline \multicolumn{1}{|c|}{ İfadeler } & $\begin{array}{c}\text { Hiçbir Önemi Yok ve } \\
\text { Az Önemli (\%) }\end{array}$ & $\begin{array}{c}\text { Çok Önemli ve Son } \\
\text { Derece Önemli (\%) }\end{array}$ & Ortalama \\
\hline $\begin{array}{l}\text { Yapacağınız iș hakkında her șeyi bilmek } \\
\text { Ve hiçbir sürprizle karșılașmamak }\end{array}$ & 11,4 & 73 & 4,91 \\
\hline $\begin{array}{l}\text { Gerçeği, doğru yanıtı ve } \\
\text { tek bir çözümü bulmak }\end{array}$ & 3,3 & 79,6 & 4,03 \\
\hline $\begin{array}{l}\text { Projeler için belirlenmiș kesin } \\
\text { zaman sınırlamalarına uymak }\end{array}$ & 4,3 & 74,9 & 3,94 \\
\hline $\begin{array}{l}\text { Yeni ve ilginç görevlerle iș rutinini } \\
\text { asma olanağına sahip olmak }\end{array}$ & 6,2 & 64 & 3,78 \\
\hline
\end{tabular}

değişikliklerden hoşlanmadıkları anlamına gelmektedir. Türk pilotlar, iş ile ilgili tüm konulara hâkim olmayı istemekte, değişimleri ve belirsizlikleri sevmemektedirler. Bu durum, Tablo 4'te de görüldüğü gibi Türk pilotlar "projeler için belirlenmiş kesin zaman sınırlamalarına uymak", "gerçeği, doğru yanıtı ve tek bir çözümü bulmak", "yapacağınız iş hakkında her şeyi bilmek ve hiçbir sürprizle karşılaşmamak" gibi değerlere çok önem vermektedirler.

\subsubsection{Kollektivizm / Bireycilik Boyutu}

Helmreich ve Merritt'in yaptığı araştırmalar pilotların içinde bulundukları üst kültürden daha bireyci özelliklere sahip olduklarını ortaya koymaktadır. Helmreich ve Merritt (2001:249) tarafından yapılan araştırmada kolektivizm/bireycilik indeksi değerleri 158-114 arasında değişmektedir. Bu araştırmada da Türk pilotların kolektivizm/bireycilik indeksi 137 olarak hesaplanmıştır. Hofstede (2000: 215) tarafından Türk kültürü için elde edilen değer (IDV=37) ile karşılaştırıldığında Türk pilotların sahip oldukları kolektivizm/bireycilik indeksi değerinin yüksek olduğunu söylemek mümkündür. Başka bir deyişle Türk pilotlar içerisinde yer aldıkları üst kültürden daha bireyci özelliklere sahiptirler. Ayrıca alan yazın incelemesi bölümünde de belirtildiği gibi Türkiye daha çok bireyci özelliklerin görüldüğü bir toplum tipine doğru değişmektedir.
Helmreich ve Merritt (2001: 72) belirsizlikten kaçınma boyutu ile ilgili araştırmalarında FMAQ içerisinde yer alan ve Tablo-5'te verilen "iş değerlerine" ilişkin tutumlardan da faydalanmışlardır.

"İş yerinizin kendiniz ve aileniz için iyi yaşam şartları sağlayan bir bölgede bulunması" ve "kendinize ve aile hayatınıza yeterince zaman kalması" ifadelerinde Tablo-5'te de görüldüğ̈̈ gibi yüksek ortalama değerlere sahip olmaları yüksek bireyci tutumlara işaret etmektedir. Söz konusu iki ifadedeki yüksek ortalamalar pilotların; örgüt dışındaki hayatlarına önem verdiklerini, kendilerine ve ailelerine yeterli zaman ayırmak istediklerini göstermektedir. Kolektivist kültürlerde bireyler içerisinde yer aldıkları örgüt ile duygusal bağ geliştirmektedirler (Hofstede, 2000: 226). Buna karşın, bireyci kültürlerde çalışanlar içinde bulundukları örgüt ile çok fazla sosyal ve duygusal bağ geliştirmeyi gereksiz görmektedir. Fakat Türk pilotlar bireyci eğilimler göstermelerine rağmen, diğer çalışanlarla iyi ilişkiler geliştirmenin oldukça önemli olduğuna inanmaktadırlar. Bu durumun kolektivist eğilimlerinden çok güç mesafesinin olumsuz etkisinin ve yapılan işin stresinin azaltılması ile ilgili olduğu düşünülmektedir. Türk pilotlar, grup içerisindeki iyi arkadaşlık ilişkileri ile otoritenin baskısını daha az hissedeceklerine inanıyor olabilirler. Yapılan görüşmelerde Türk pilotların birçoğu iş sırasındaki stres ve yorgunluğu iyi arkadaşlık 


\section{Tablo 5}

Kolektivizm/Bireycilik ile ilgili İş Değerleri

\begin{tabular}{|c|c|c|c|c|}
\hline İfadeler & 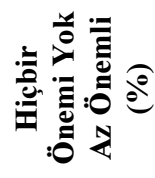 & 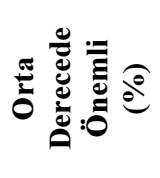 & 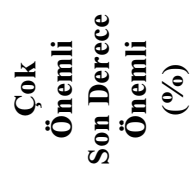 & 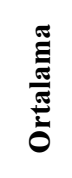 \\
\hline $\begin{array}{l}\text { Kendinize ve aile hayatınıza yeterince } \\
\text { zaman kalması }\end{array}$ & --- & 7,6 & 92,4 & 4,35 \\
\hline $\begin{array}{l}\text { İș arkadaşlarıyla veya ekip üyeleriyle } \\
\text { iyi kișisel ilișkiler sürdürmek }\end{array}$ & 0,5 & 10,4 & 89,1 & 4,34 \\
\hline $\begin{array}{l}\text { İș yerinizin kendiniz ve aileniz için iyi yaşam } \\
\text { șartları sağlayan bir bölgede bulunması }\end{array}$ & 1,9 & 10 & 88,1 & 4,23 \\
\hline
\end{tabular}

ilişkileri ile daha az hissettiklerini belirtmişlerdir.

Diğer yandan Türk Pilotların kolektivizm/bireycilik boyutundaki durumları hakkında bilgi edinebilmek için Tablo-6'da verilen tutum ifadelerinden de yararlanılmıştır. "Uçuşla ilgili bir problem olduğunu fark edersem, kimin alınıp üzüleceğine bakmaks1zin bunu dile getiririm" ifadesinde elde edilen ortalamaların yüksek olması bireyci eğilimlerin ağır bastığını göstermektedir.

Kolektivist ülkelerde pilotlar grup içerisindeki uyumu bozmamak için çoğunluğun fikirlerini onaylamakta ve düşündüğü farklı şeyleri söylemekten çekinmektedir. Fakat Türk pilotlar, fikirlerini ifade etme konusunda grup uyumunu engel görmemektedirler. $\mathrm{Bu}$ ifadeye verilen cevapların yüksek ortalamalara sahip olmasının hem bireyci eğilimlerin hem de meslek kültürünün bir sonucu olabileceği düşünülmektedir. Uçuş emniyetinin sağlanması, meslek kültürü içerisinde önemli bir değerdir. Meslek kültürünün etkisi ile Türk pilotlar, uçuş emniyetini grup uyumunun önünde tutuyor olabilirler. Türk pilotlar, uçuş ile ilgili bir problem tespit ettiklerinde grup içerisindeki ilişkileri etkilese bile bu durumu söylemeyi doğru bulmaktadır.

"Diğer ekip üyeleri ile aynı fikirde olmak farklı bir fikir bildirmekten daha iyidir" ifadesinde sahip olunan düşük ortalamalar Türk pilotların bireyci değerlere sahip olduklarına işaret eden diğer bir bulgudur. Türk pilotlar

\section{Tablo 6}

Kolektivizm/Bireycilik İle İlgili İfadeler

\begin{tabular}{|c|c|c|c|c|}
\hline $\begin{array}{l}\text { Kolektivizm/Bireycilik } \\
\text { İle İlgili İfadeler }\end{array}$ & 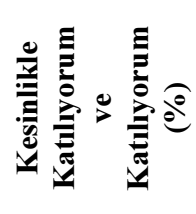 & 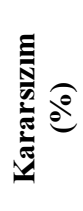 & 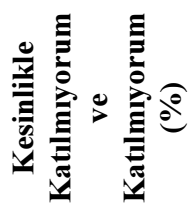 & 嶂 \\
\hline $\begin{array}{l}\text { Uçușla ilgili bir problem olduğunu fark } \\
\text { edersem, kimin alınıp üzüleceğine } \\
\text { bakmaksızın bunu dile getiririm }\end{array}$ & 89,1 & 5,7 & 5,2 & 4,31 \\
\hline $\begin{array}{l}\text { Diğer ekip üyeleri ile aynı fikirde } \\
\text { olmak farklı bir fikir bildirmekten } \\
\text { daha iyidir }\end{array}$ & 10 & 5,2 & 84,8 & 1,93 \\
\hline
\end{tabular}


grup uyumunu bozmama adına fikirlerini ifade etmemeyi doğru bulmamaktadırlar. Bu anlamda her iki ifadeden elde edilen cevaplar Türk pilotların içinde yer aldıkları üst kültüre göre daha bireyci değerlere sahip olduklarına işaret etmektedir.

6.3. Türk Pilotların Ulusal Kültür Boyutlarının Hofstede ve Helmreich Araştırmalarının Bulguları ile Karşılaştırılması

Helmreich ve Merritt (2001) bireycilik (IDV), güç mesafesi (PDI) ve belirsizlikten kaçınma (UAI) indekslerinin oluşturulmasında Hofstede'in kullandığı yönteme bağlı kalmaya çalışmışlar ve elde ettikleri değerleri sıralayarak ülkelerin birbirlerine göre kültürel boyutlardaki durumlarını ortaya koymuşlardır. Ayrıca elde edilen bu değerler, daha önce Hofstede'in dört kültürel boyutta elde ettiği bulgularla karşılaştırılmıştır. Böylece, iki araştırma arasındaki süreçte ülkelerin dört boyutta sahip oldukları kültürel değerlerde bir değişme olup olmadığ 1 saptanmaya çalışılmiştır.

Bu çalışmada ise Türk pilotların sahip olduğu güç mesafesi, bireycilik ve belirsizlikten kaçınma indeksleri saptanmıştır. Türk pilotlar ile ilgili elde edilen değerler, Hofstede (2000) ve Teksas Üniversitesi tarafından elde edilen sonuçlarla karşılaştırılmıştır. Helmreich ve Merritt'in (2001) erkeklik dişilik boyutunda elde ettikleri değerler Hofstede (2001: 286) tarafından ortaya konan sonuçlarla benzeşim göstermediği için bu çalışma kapsamında Türk pilotların erkeklik-dişilik boyutundaki eğilimleri incelenmemiştir. Tablo-7'de Hofstede (2000) ile Helmreich ve Merritt'in (2001) çalışmalarında ortak olan ülkelerin değerleri verilmiştir. Bu çalışmada elde edilen değerler de "Türkiye'nin değerleri" olarak bu tabloya eklenmiştir.

Tablo-7'de görüldüğü gibi Hofstede (2000: 215), Türkiye'nin bireycilik indeksini 37 olarak belirlemiştir. Türkiye toplam 22 ülke içinde 15. sırada yer almıştır. Bu durum ülkemizin ortaklasa davranış̧̧ ülkeler arasında olduğunu göstermektedir. Hofstede (2000: $215)^{\prime}$ in belirlediği bireycilik indeksine göre Türkiye 22 ülke arasında 15'inci sırada yer al- maktadır. Diğer yandan, Teksas Üniversitesi tarafindan yapılan araştırmalarda pilotların kendi ulusal kültürlerine göre daha yüksek bireycilik indekslerine sahip oldukları saptanmıştır. Türk pilotların bireycilik indeksi 137 olarak belirlenmiştir. 22 farklı ülkeden pilotlarla karşılaştırıldığında Türk pilotların bireycilik indeksi sıralamasında Tayvanlı pilotlar ile birlikte 10'uncu oldukları görülmektedir. Bu durum Türk pilotların içerisinde yer aldıkları üst kültüre göre daha bireyci özelliklere sahip olduklarına işaret etmektedir. Bununla birlikte bu sonuç Türk kültürünün zaman içinde daha bireyci özellikler kazanmaya başlamış olmasına da işaret ediyor olabilir. Türk pilotların diğer ülkelerin pilotları arasında ortalama bir yerde oldukları söylenebilir.

Diğer yandan Hofstede (2000: 87), Türkiye'nin güç mesafesi indeksini 66 olarak belirlemiştir. Hofstede tarafından elde edilen bulgular 22 ülke içerisinde en yüksek güç mesafesi indeksinin 104 olduğunu göstermektedir. Türkiye bu siralamada 6 . sirada yer almıştır. Teksas Üniversitesi tarafından pilotlar üzerinde yapılan araştırmada en yüksek güç mesafesi değeri 125 olarak belirlenmiştir. Bu çalışmada ise, Türk pilotların güç mesafesi 95 olarak hesaplanmıştır. Diğer ülkelerin güç mesafesi değerleri ile karşılaştırıldığında Türk pilotlar yine 6. sırada yer almaktadır. Bu durum Türk pilotların sahip olduğu güç mesafesi değerlerinin Teksas Üniversitesi araştırmasında yer alan birçok ülkeden daha yüksek olduğunu göstermektedir. Dikkat çeken diğer bir nokta ise Türk pilotların güç mesafesi değerinin çalışma kapsamındaki tüm Avrupa ülkeleri değerlerinden daha yüksek olduğudur.

Belirsizlikten kaçınma boyutunda ise Hofstede (2000: 215), ülkemizin sahip olduğu indeks değerini 85 olarak belirlemiştir. Hofstede (2000: 215) tarafindan elde edilen bulgular 22 ülke içerisinde en yüksek belirsizlikten kaçınma değerinin 112 olduğunu göstermektedir. Türkiye Hofstede (2000: 215)'in elde ettiği değerlere göre yapılan sıralamada 4 . siradadır. Bu çalışmada Türk pilotların belirsizlikten kaçınma değeri ise 96 olarak hesaplanmıştır. 
Tablo 7

Ülkelerin Bireycilik, Güç Mesafesi ve Belirsizlikten Kaçınma Sıralaması

\begin{tabular}{|c|c|c|c|c|c|c|c|c|c|c|c|c|}
\hline & \multicolumn{4}{|c|}{ Kollektivizm / Bireycilik } & \multicolumn{4}{|c|}{ Güç Mesafesi } & \multicolumn{4}{|c|}{ Belirsizlikten Kaçınma } \\
\hline & $\mathbf{H}$ & HS & TÜ & TÜS & $\mathbf{H}$ & HS & TÜ & TÜS & $\mathbf{H}$ & HS & TÜ & TÜS \\
\hline A.B.D. & 91 & 1 & 152 & 5 & 40 & 11 & 52 & 16 & 46 & 14 & 47 & 7 \\
\hline Almanya & 67 & 11 & 131 & 12 & 35 & 13 & 84 & 9 & 65 & 8 & 41 & 10 \\
\hline Arjantin & 46 & 13 & 153 & 4 & 49 & 10 & 89 & 8 & 86 & 3 & 30 & 13 \\
\hline Avustralya & 90 & 2 & 158 & 1 & 36 & 12 & 36 & 19 & 51 & 11 & 42 & 9 \\
\hline Brezilya & 38 & 14 & 126 & 14 & 69 & 5 & 125 & 1 & 76 & 6 & 56 & 5 \\
\hline Danimarka & 74 & 6 & 143 & 8 & 18 & 18 & 29 & 20 & 23 & 19 & 29 & 14 \\
\hline Fas & 20 & 20 & 133 & 11 & 77 & 4 & 103 & 3 & 54 & 10 & 66 & 4 \\
\hline Filipinler & 32 & 17 & 145 & 7 & 94 & 2 & 100 & 4 & 44 & 15 & 40 & 11 \\
\hline G.Afrika & 65 & 12 & 137 & 10 & 49 & 10 & 44 & 17 & 49 & 13 & 26 & 17 \\
\hline G.Kıbrıs & 35 & 16 & 127 & 13 & 60 & 6 & 63 & 12 & 112 & 1 & 51 & 6 \\
\hline Hong Kong & 89 & 3 & 154 & 3 & 35 & 13 & 59 & 14 & 35 & 17 & 37 & 12 \\
\hline İrlanda & 70 & 8 & 147 & 6 & 28 & 16 & 55 & 15 & 35 & 17 & 20 & 19 \\
\hline İsveç & 71 & 7 & 157 & 2 & 31 & 15 & 36 & 19 & 29 & 18 & 9 & 20 \\
\hline İsviçre & 68 & 10 & 145 & 7 & 34 & 14 & 65 & 11 & 58 & 9 & 20 & 19 \\
\hline İtalya & 76 & 5 & 131 & 12 & 50 & 9 & 72 & 10 & 75 & 5 & 42 & 9 \\
\hline Japonya & 46 & 13 & 152 & 5 & 54 & 8 & 62 & 13 & 92 & 2 & 41 & 10 \\
\hline Kore & 18 & 21 & 114 & 16 & 60 & 6 & 105 & 2 & 85 & 4 & 84 & 2 \\
\hline Malezya & 26 & 19 & 118 & 15 & 104 & 1 & 99 & 5 & 36 & 16 & 42 & 8 \\
\hline Meksika & 30 & 18 & 139 & 9 & 81 & 3 & 100 & 4 & 82 & 5 & 28 & 16 \\
\hline Norveç & 69 & 9 & 157 & 2 & 31 & 15 & 17 & 21 & 50 & 12 & 25 & 18 \\
\hline Tayvan & 17 & 22 & 137 & 10 & 58 & 7 & 90 & 7 & 69 & 7 & 73 & 3 \\
\hline Türkiye & 37 & 16 & 137 & 10 & 66 & 6 & 95 & 6 & 85 & 4 & 96 & 1 \\
\hline $\begin{array}{l}\text { Yeni } \\
\text { Zelanda }\end{array}$ & 79 & 4 & 152 & 5 & 22 & 17 & 41 & 18 & 49 & 13 & 29 & 15 \\
\hline
\end{tabular}

H : Hofstede tarafindan belirlenen indeks.

HS : Hofstede tarafından yapılan indekse göre sıralama.

Pilotların belirsizlikten kaçınma indeksi değeri Teksas Üniversitesi tarafından elde edilen sonuçlarla karşılaştırıldığında ise Türkiye'nin 1'inci sırada yer aldığı görülmektedir. Oldukça çarpıcı olan bu bulgu Türk pilotların belirsizlikten kaçınma tutumlarının çok yüksek olduğunu göstermektedir.

6.4. Meslek Kültürünün Türk Pilotlar Üzerindeki Etkisi

Helmreich ve Merritt (2001: 30), farklı kül-
TÜ : Teksas Üniversitesi tarafından belirlenen indeks.

TÜS : Teksas Üniversitesi tarafından yapılan indekse göre siralama

türel özelliklerden gelmelerine rağmen, pilotların bazı ortak tutumlara sahip oldukların belirlemişlerdir. Bu durum Helmreich ve Merritt (2001: 30) tarafından meslek kültürünün bir sonucu olarak değerlendirilmektedir. Teksas Üniversitesi çalışmalarında ve bu araştırmada Türk pilotlara ilişkin olarak elde edilen ortak tutum bilgileri Tablo-8'de verilmektedir.

Meslek kültürünün bir sonucu olarak, araştırmaya katılan pilotların önemli bir bö- 
Tablo 8

Türk Pilotların Meslek Kültürü ile İlgili Değerleri

\begin{tabular}{|c|c|c|}
\hline $\begin{array}{l}\text { Pilotların Genel Olarak } \\
\text { Katıldıkları İfadeler }\end{array}$ & $\begin{array}{c}\text { Teksas Üniversitesi Katılıyorum } \\
\text { ve } \\
\text { Kesinlikle Katılıyorum Oranları (\%) }\end{array}$ & $\begin{array}{l}\text { Türk Pilotlar } \\
\text { Oran (\%) }\end{array}$ \\
\hline $\begin{array}{l}\text { Kokpit ve kabin ekipleri arasında } \\
\text { eș güdümü sağlamak kaptanın } \\
\text { sorumlulukları arasındadır. }\end{array}$ & $\% 85$ 'den fazlası & $\% 95,8$ \\
\hline $\begin{array}{l}\text { İyi iletișim ve ekipler arası eș güdüm } \\
\text { uçuș emniyetinin sağlanmasında teknik } \\
\text { beceri kadar önemlidir. }\end{array}$ & $\% 85$ 'den fazlas & $\% 98,1$ \\
\hline $\begin{array}{l}\text { Performansımı etkileyen konularda } \\
\text { bana danıșılmasını beklerim. }\end{array}$ & $\begin{array}{l}32 \text { havayolu pilotlarının } \% 85 \text { 'den fazlası } \\
\text { Japon pilotlar } \% 76\end{array}$ & $\% 90,9$ \\
\hline $\begin{array}{l}\text { Ekip üyeleri birbirlerinin stres } \\
\text { ve yorgunluk belirtilerini } \\
\text { gözlemlemelidirler. }\end{array}$ & $\begin{array}{l}31 \text { havayolu pilotlarının } \% 85 \text { 'den fazlası } \\
\text { İtalyan pilotlar } \% 82 \\
\text { Meksikalı pilotların } \% 82 \text { 'si }\end{array}$ & $\% 98,6$ \\
\hline $\begin{array}{l}\text { Uçuşla ilgili bir problem tespit edersem } \\
\text { kimin alınıp üzüleceğine bakmaksızın } \\
\text { bunu dile getiririm }\end{array}$ & $\begin{array}{l}29 \text { havayolu pilotlarının \%85'den fazlası } \\
\text { Tayvanlı pilotlar \%84, Brezilyalı pilotlar } \% 81 \\
\text { Japon pilotlar } \% 49 \text {, Koreli pilotlar } \% 36\end{array}$ & $\% 89,1$ \\
\hline $\begin{array}{l}\text { Pilotların Genel Olarak } \\
\text { Katılmadıkları İfadeler }\end{array}$ & $\begin{array}{c}\text { Teksas Üniversitesi Katılmıyorum } \\
\text { ve } \\
\text { Kesinlikle Katılmıyorum Oranları (\%) }\end{array}$ & \\
\hline $\begin{array}{l}\text { Ekip üyelerini soru sormaları } \\
\text { konusunda teşvik eden } \\
\text { kaptanlar zayıf liderlerdir. }\end{array}$ & $\begin{array}{l}30 \text { havayolu pilotlarının } \% 85 \text { 'den fazlası } \\
\text { Arjantinli pilotlar } \% 79 \text {, Meksikalı pilotlar } \% 82 \\
\text { Faslı pilotlar } \% 73\end{array}$ & $\% 95,2$ \\
\hline $\begin{array}{l}\text { Ekip içindeki genç ve tecrübesiz pilotlar } \\
\text { kaptanın veya daha kıdemli diğer ekip } \\
\text { üyelerinin kararlarını sorgulamamalıdırlar. }\end{array}$ & $\begin{array}{l}29 \text { havayolu pilotlarının } \% 85 \text { 'den fazlası } \\
\text { Brezilyalı pilotlar } \% 78 \text { ve } \% 77 \\
\text { Meksikalı pilotlar } \% 74 \text {, Filipinli pilotlar } \% 80\end{array}$ & $\% 80,1$ \\
\hline $\begin{array}{l}\text { Diğer ekip üyeleri ile aynı fikirde olmak } \\
\text { farklı bir fikir bildirmekten iyidir. }\end{array}$ & $\begin{array}{l}29 \text { havayolu pilotlarının } \% 85 \text { 'den fazlası } \\
\text { Tayvanlı pilotlar } \% 78 \text {, Güney Koreli pilotlar \%69 } \\
\text { Meksikalı pilotlar \%72 }\end{array}$ & $\% 84,8$ \\
\hline
\end{tabular}

lümü ekip içerisinde eş güdümün sağlanmasinın kaptanların sorumlulukları arasında olduğunu belirtmektedir. Türk pilotların \%95,8'i “ "kokpit ve kabin ekipleri arasında koordinasyonu sağlamak kaptan pilotun sorumlulukları arasındadır" ifadesine "katılıyorum" ve "kesinlikle katılıyorum" şeklinde cevap vermişlerdir.

Meslek kültürü ile ilgili elde edilen bulgular, Türk pilotların da diğer pilotlar gibi iletişim ve koordinasyonun uçuş emniyetinde teknik beceriler kadar önemli bir yere sahip olduğunu düşündüklerini göstermektedir. Araştırmaya katılan Türk pilotların \%90'ından fazlası, iletişim ve koordinasyon ile ilgili becerilerin emniyetli bir uçuşun yürütül- mesinde en az teknik beceriler kadar önemli olduğu ile ilgili ifadeye "kesinlikle katılıyorum" cevabını vermişlerdir.

Uçuş sırasında kaptan pilotlar tarafından alınan kararlar veya üst yönetimin belirlediği uygulamalar, diğer ekip üyelerinin performansı üzerinde etkili olmaktadır. Pilotlar, performanslarını etkileyebilecek düzenlemeler yapılmadan önce kendilerinin de fikirlerinin alınması gerektiğini düşünmektedirler. $\mathrm{Bu}$ durum, pilotların açık iletişimin gerekliliği ile ilgili olumlu tutumlara sahip olduklarını göstermektedir. Türk pilotları \%90'1 söz konusu ifadeye "katıliyorum" ve "kesinlikle katılıyorum" cevabını vermişlerdir.

Türk pilotlar uçuş sırasında diğer ekip üye- 
lerinin stres ve yorgunluk düzeylerini takip etmeyi gerekli bulmaktadırlar. Bu durum, meslek kültürünün uçuş emniyeti üzerindeki olumlu bir etkisidir. Pilotlar, birbirlerinin stres ve yorgunluk düzeylerini takip ederek potansiyel hataların ortaya çıkmasını engellemeyi amaçlamaktadırlar. Araştırmaya katılan Türk pilotların $\% 98,6$ 's1 "ekip üyeleri birbirlerinin stres ve yorgunluk belirtilerini gözlemlemelidirler" ifadesine "katıliyorum" ve "kesinlikle katılıyorum" cevabını vermişlerdir.

Daha önce de belirtildiği gibi diğer ekip üyelerinin soru sormalarını teşvik eden kaptan pilotların zayıf liderler olarak düşünülmesinin açık iletişimi ve dolayısıyla EKY' yi olumsuz yönde etkilediğini belirtmektedir. Bu araştırmaya katılan pilotların önemli bir bölümünün "diğer ekip üyelerinin fikir belirtmelerini teşvik eden kaptanlar zayıf liderlerdir" ifadesine çoğunlukla katılmamaları, Türk pilotların açık iletişimin gerekli olduğuna inandıklarını göstermektedir.

Soru formuna cevap veren Türk pilotların \%95'inden fazlası, söz konusu ifadeye "katılmiyorum" ve "kesinlikle katılmiyorum" cevabını vermişlerdir. Bu durum, Türk pilotların dünyadaki diğer pilotlar gibi, uçuş sırasında diğer ekip üyelerinin rahatça soru sorabilecekleri bir ortam yaratılmasının gerekliliğine inandıklarını göstermektedir. Bu durumu, meslek kültürünün uçuş emniyetinin sağlanmasındaki en güçlü yönü olarak tanımlamak mümkündür. Diğer yandan, "ekip içerisindeki astlar (genç ve tecrübesiz pilotlar) kaptanın veya daha kıdemli ekip üyelerinin kararlarını sorgulamamalıdır" ifadesine verilen cevaplar da Türk pilotların açık iletişim ile ilgili olumlu tutuma sahip olduklarını doğrulamaktadır.

Meslek kültürünün etkisi ile Türk pilotların açık iletişime verdikleri önemin uçuş emniyetinin sağlanmasına büyük avantaj sağlayacağı düşünülmektedir. Türk pilotların meslek kültürü ile ilgili ifadelere katılımı oldukça yüksektir. Bu araştırmada Türk pilotların tutumları üzerinde meslek kültürünün etkisini belirlemeye yönelik ifadelere verilen cevaplar, Helmreich ve Merritt (2001: 247) tarafindan elde edilen bulgularla önemli bir benzerlik göstermektedir.

\section{SONUÇ}

Bu araştırmada elde edilen sonuçlar, Türk pilotların yüksek güç mesafesine sahip olduklarını göstermektedir. Otokratik liderlik biçimi çok yaygındır ve pilotlar çoğu zaman üstlerine aynı fikirde olmadıklarını söylemek konusunda çekingen davranmaktadırlar. Güç mesafesinin bu denli yüksek olması EKY için olumsuz bir durum oluşturmaktadır. Bu nedenle, yapılacak EKY eğitimlerinde yüksek güç mesafesinin yol açacağı tehlikeleri ortadan kaldıracak tutum ve davranışların geliştirilmesine odaklanılmalıdır. EKY eğitimlerinde, otokratik liderlik tarzı yerine diğer ekip üyelerinin de karar verme süreçlerine katılımlarının sağlandığı liderlik tarzlarının geliştirilmesi sağlanmalıdır. Diğer yandan, ekip üyelerinin otomasyona aşırı güvenleri de uçuş emniyetini tehlikeye atabilir. $\mathrm{Bu}$ nedenle, EKY eğitimleri içerisinde ekip üyelerinin otomatik sistemler tarafından üretilen sonuçları sorgulamaları gerektiği vurgulanmalıdır.

Ekip üyelerinin kurallara uyum eğilimleri veya beklenmedik durumlara müdahale şekilleri sahip oldukları belirsizlikten kaçınma değerleri ile şekillenmektedir. Bu nedenle EKY eğitimlerinin tasarlanmasında ekip üyelerinin belirsizliğe karsı gösterdikleri tolerans da göz önünde tutulmalıdır. Bu araştırmada, Türk pilotların belirsizlikten kaçınma değerlerinin çok yüksek olduğu saptanmıştır. Türk pilotların belirsizlikten kaçınma eğilimlerinin yüksek olması, standart işletim prosedürlerinin uygulanmasını kolaylaştırır. Diğer yandan, belirsiz durumlar Türk pilotlar için oldukça fazla stres yaratmaktadır.

Strese karsı toleransın düşük olması, acil ve olağanüstü durumlarda ekip üyelerinin hata yapabilmelerine neden olabilirken, yaratıcı çözümler geliştirmelerine de engel olacaktır. Bu nedenle, EKY eğitimleri ile Türk pilotların acil ve olağanüstü durumlarda inisiyatif kullanma ve stresle basa çıma konusundaki tutumları üzerine odaklanılmalıdır.

Diğer bir kültürel boyut olan kolektivizm ise, uçuş sırasında pilotların davranışları üzerinde etkili olmaktadır. Bu araştırmada elde 
edilen sonuçlardan Türk pilotların içinde bulundukları ulusal kültürden farklı olarak daha bireyci oldukları saptanmıştır. Ülkemizde de giderek bireyci değerlerin benimsendiği ve bu durumun pilotlar arasinda daha yaygin bir durumda olduğu söylenebilir. Bireycilik ekip üyelerinin, birbirlerinin kararlarını sorgulamalarını ve hiyerarşik sınırları daha az hissetmelerini sağlamaktadır. Bu bakıș açısı ile uçuş emniyetinin artabileceği söylenebilir. Buna karsın takım çalışması etkinliğinin azalması durumunda havacilık emniyeti de azalabilecektir. Bu nedenle, ülkemizde yapılacak EKY eğitimlerinde takım çalışmasının önemi daha çok vurgulanmalıdır.

Ulusal kültürün yanı sıra meslek kültürü ile ilgili elde edilen bulgular, Türk pilotların önemli bir bölümümün birçok konuda dünyadaki diğer pilotlar ile aynı tutumlara sahip olduklarını göstermektedir. Türk pilotlar, iletişimin uçuş emniyetinin sağlanmasında oldukça önemli olduğuna inanmaktadırlar. Bu anlamda Türk pilotların, iletişimin teknik beceri kadar önemli olduğuna, kaptanların ekip içerisinde koordinasyonu sağlamaları ve soru sormayı teşvik etmeleri gerektiğine inandıkları görülmektedir. Bu durum, tüm dünyada olduğu gibi Türkiye'de de EKY eğitimleri için oldukça olumlu bir durumdur.

Türkiye'deki sivil havacilık otoritesi CRM eğitimlerinin sadece yapılıp yapılmad1ğını sorgulamaktadır. Bununla birlikte çalışmadan elde edilen bulgular CRM programlarm etkinliklerinin ve bunların ulusal kültür özelliklerine uygun olup olmadıklarının da araştırılmasının gereklilik olduğu sonucunu doğurmaktadır. Aksi halde CRM eğitimlerinin uçuş emniyetini artırmaya yönelik amaca ulaşmada yeterince başarılı olması beklenmemelidir.

\section{References}

DASTMALCHIAN, Ali ve KABASAKAL, Hayat (2001), "Special Issue on Leadership and Culture in the Middle East: Norms, Practices and Effective Leadership Attributes in Iran, Kuwait, Turkey and Qatar", Applied Psycology: An International Review, 5 (4):532-558

ELBAŞI, Dinçer (2003), “Ekip Kaynak Yönetimi: Uçuş Ekipleri Tarafından Kaynak Yönetimi Programlarının Uygulanmasında Karşılaşılan Sorunların Tespit ve Çözümüne İlişkin Bir Araştırma", Çukurova Üniversitesi, Aralık, Yayınlanmamış Yükseklisans Tezi.

GOODE, William J. (1957), "Community within a Community: The Professions," American Sociological Review 22; Aktaran: HELMREICH, RL. (2000) "Culture and Error in Space: Implications From Analog Environments," Aviation,Space, and Environmental Medicine, 9-11(71): 133-139

GÜMÜŞ, Ali (1998), “İnsan Hatalarının Belirlenmesinde Kullanılan Tekniklerin İncelenmesi ve bir Endüstriyel Uygulama," Gazi Üniversitesi, Yayınlanmamış Yüksek Lisans Tezi.

GÜVENÇ, Bozkurt (1999), İnsan ve Kültür, Remzi Kitabevi Yayınları, İstanbul.

HAWKINS, Frank H. (2002), Human Factors in Flight, İkinci basım, Ashgate Publishing Limited, Aldershot.

HELMREICH, RL ve FOUSHEE, HC. (1993), Why crew resource management? Empirical and theoretical bases of human factors in training and aviation, Calif: Academic Press; San Diego. Aktaran: HELMREICH, RL. ve MERRITT, Asleigh C. (2001), Culture at Work in Aviation and Medicine Ashgate Publishing Company, Aldershot. 
HELMREICH, RL, WILHELM, John A., vd. (2001), "Culture, Error, and Crew Resource Management," University of Texas at Austin Human Factors Research Project: 254, http://homepage.psy.utexas.edu/homepage/group/Helmreich LAB, (15.04.2004).

HELMREICH, RL. (Basım aşamasında) "Culture, threat, and error: Assessing system safety. In Safety in Aviation: The Management Commitment: Proceedings of a Conference. London: Royal Aeronautical Society", http:/ /homepage.psy.utexas.edu/homepage/group/helmreichla b/Publications/pubfiles/Pub257.pdf (30.08.2004)

HOFSTEDE, Geert. (2000), Cultures Consequences, Comparing Values, Behaviors, Institutions and Organizations Across Nations İkinci basım, Sage Publications, London.

HOFSTEDE, G. ve SOETERS, J. (2002), “Consensus Societies with their own Character: National Cultures in Japan and The Netherlands," Comparative Sociology, 1(1): 1-17

KARAKİTAPOĞLU, Zahide vd., (2002), "Value Domains of Turkish Adults and University Students," The Journal of Social Psychology, 142 (3): 333-351

KIRAÇ, Yavuz "Büro Yönetiminde Ergonomi ve Ergonominin Verimliliğe Etkisi: Emniyet Müdürlüğü'nde bir Uygulama," Gazi Üniversitesi, Yayınlanmamiş Yüksek lisans Tezi, Ankara.

LAUBER, J. (1984), Resource Management in the Cockpit", Air Line Pilot, vol.53: Aktaran FLIN, R., O'CONNOR, P., ve MEARNS, K. (2002). Crew resource management: Improving safety in high reliability industries. Team Performance Management, 8(3-4): 68-78
ROGELBERG, Steven G. (2007), Encyclopedia of Organizational Psychology SAGE Publications, California.

SARGUT, Selami (2001), Kültürler Arası Farklılaşma ve Yönetim İkinci basım, İmge Kitabevi Yayınları, Ankara.

SCHWARTZ, Shalom H. (1999), "A Theory of Cultural Values and Some Implications for Work", Applied Psychology: An International Review, 48 (1): 23-47

WASTI, Syeda Arzu (1998), "Cultural Barriers in the Transferability of Japanese and American Human Resources Practices to Developing Countries: The Turkish Case", The International Journal of Human Resource Management, 9, (4): 608-631 